\title{
Teacher performance evaluation: a stressful experience from a private secondary school
}

\section{Ayse Bas Collins}

To cite this article: Ayse Bas Collins (2004) Teacher performance evaluation: a stressful experience from a private secondary school, Educational Research, 46:1, 43-54, DOI: $10.1080 / 0013188042000178818$

To link to this article: http://dx.doi.org/10.1080/0013188042000178818

册 Published online: 04 Jun 2010.

Submit your article to this journal $\square$

Џlll Article views: 334

Q View related articles $\circlearrowright$

4 Citing articles: 5 View citing articles 


\title{
Teacher performance evaluation: a stressful experience from a private secondary school
}

\author{
Ayse Bas Collins* \\ Bilkent University, Ankara, Turkey
}

The study examines aspects of centralized and school-based supervision (SBS) as carried out at a private secondary school. Data were gathered from administrators, teachers and students through interviews, critical incidents and pertinent documentation. The study points out that a combination of the two supervision systems offers benefits that a single, stand-alone system cannot, while highlighting the problems and the dilemma teachers find themselves in when faced with two systems of a summative nature. The study concludes that centralized and SBS can co-exist. They, however, must complement each other, not duplicate functions.

Keywords: Teacher supervision; School improvement; School assessment; Secondary school teacher supervision

\section{Introduction}

Teacher accountability, administration accountability, centralized and decentralized teacher inspection, nationalized education supervision, school-based supervision (SBS), site-based supervision, administrative control, professional control, community control and comprehensive system of inspection - so many terms, and the list goes on and on. In essence, what are we talking about? Why the concern? What are the benefits? What are the pitfalls? So many questions: it is a never-ending quest to provide quality education that meets students' and society's needs, as a whole, while balancing educators' professional and personal needs within finite monetary constraints.

In recent years, educational systems of various countries have experimented with different methodologies in an attempt to optimize teacher performance. Some have taken purist approaches on both sides of the spectrum, whereas some have mixed aspects. We are speaking of centralized versus decentralized educational systems, with their separate and distinct teacher inspection and/or supervision approaches. Teacher assessment methodologies of the two systems vary in both intent and style. Understanding assessment of the driving forces (that being teachers) is essential.

The centralized system relies on inspections by which inspectors, drawn from the

${ }^{\star}$ Hosdere cad., Cankaya Evleri, D Blok, Daire 1, Yukari Ayranci, 06550, Ankara, Turkey. Email: Collins54@hotmail.com 
country's senior teaching staff, visit schools, observe classes, gather data and evaluate teacher performance (Wilson, 1995), whereas decentralization can be characterized as having little control imposed by national governments, other than through guidelines. Control of curriculum, teaching methodology and teacher assessment, and even finance, remains in the control of localized government. Like the centralized system, decentralization has experienced an evolution, in which present needs have shifted certain aspects towards a more centralized, controlled system. Teacher accountability is one of these aspects.

As educators, we are subjugated to whichever system our legislative or administrative body of government dictates. For the most part, we are impotent to change the system and therefore bound to make the best of the system imposed. Regardless of whatever system is applied, a method of teacher evaluation is necessary. As Knapp (1982) has stated, the pressure to improve teaching performance may foster more elaborate systems, but it may force summative thrusts rather than formative efforts. However, teacher appraisal systems should be directed towards improvement and not termination (Poster, 1991).

The body of models is extensive. The literature presents various classifications of models for instructional supervision. The first classification offers four approaches: scientific (Barr et al., 1961; Carroll, 1963; Dewey, 1929; Gagné, 1967), clinical (Cogan, 1973; Garman, 1982), artistic (Eisner, 1982) and eclectic (Sergiovanni, 1982). Oliva (1989) groups supervision into three categories: scientific management, laissez-faire and group dynamics. Another classification is offered by Poster (1991): developmental, laissez-faire, managerial and judgemental. Furthermore, different authors give similar definitions to their suggestions such as evaluation for professional development (Duke \& Stiggins, 1990), evaluation for career awards and merit pay (Bacharach et al., 1990), evaluation for tenure and dismissal (Bridges, 1990) and evaluation for school improvement (Iwanicki, 1990).

All these classifications have some similarities. First, they depend on whether the organization is strictly structured with bureaucratic levels or non-structured, fostering creative atmospheres where individual dynamics are cultivated. The two tangents either create an air of self-starters and risk-takers, or a realm of uniformity, with little creativity left to individual teachers. Secondly, authors argue different points of view related to different philosophical perspectives and epistemological beliefs, some of which emphasize the needs of the organization and some the needs of individuals within the organization, and some the needs of both.

\section{Turkish private school system}

As in most countries, one of secondary education's prime goals is to prepare students for entry into universities, and Turkish schools are no different. They direct their energies towards student preparation for competitive university entrance examinations. There is a significant difference between private and public secondary school when considering acceptance into universities. Private secondary schools have an acceptance rate of $62.9 \%$, compared to only $18.4 \%$ from public secondary schools (MoE, 1999). 
Both private and public schools are administered by the centralized Ministry of Education (MoE), which determines many procedures such as school policies, regulations, curriculum standards and teacher supervision. The MoE employs 310 inspectors to evaluate 140000 secondary school teachers (MoE, 1999). Inspection is conducted in two areas: administrative and classroom teacher assessment.

There are prime differences between teachers in the public and private school systems. The public school teachers are part of the civil service branch of government, and, once accepted, there is little likelihood of dismissal, whereas private school teachers are hired on yearly contracts that require more credentials and greater performance levels. Private schools do not rely on the central system for total monetary support; however, their licensing depends on strict compliance with $\mathrm{MoE}$ standards. The private sector has recognized problems with the centralized inspection system. Stakeholders have imposed higher demand for improved teacher performance, therefore, the 'school-based supervision system' (SBSS) has been enacted to update and maintain the quality of teachers. Within this process organizational members, such as the principals and/or department heads, have assumed the responsibility for evaluating teachers.

To sum up, teachers at private schools are responsible to the MoE to maintain professional accreditation, and to the school administration to keep their school position.

This case study was conducted at one private secondary school to review the effectiveness and impacts of those systems. The following research questions were posed as the basis of the study:

1 How are MoE inspection and SBS perceived by the administrators, department/ assistant heads, teachers and students in terms of weaknesses and strengths?

2 What impact do these systems have on the teaching and learning process, teacher development and overall school improvement?

\section{Methodology}

Case-study methods and procedures were used in the research. The participants were:

- members of the administrative board (2);

- the principal;

- all assistant heads (6) and department heads (6);

- teachers (30 out of 78 full-time teachers) who were chosen from each department according to their experience in the field and in the school, their gender and school level taught;

- students (50 out of 1259).

Three qualitative data collection techniques, namely interview, critical incident and the related document review, were used. Interview schedules were designed for each subject group based on the research questions. Each interview schedule consisted of 25 questions reviewing the perceptions and impacts of MoE inspection and SBS. Moreover, the principal and the teachers were asked to transcribe their thoughts regarding what they considered successful and unsuccessful supervisory experiences 
on a 'critical incident' form. The school documents, including announcements, school prospectus, school-based training programmes, administrative documents and student instructor evaluation form, were reviewed.

Data were subjected to 'content analysis' to explore the patterns of perception and the school's supervisory process and practices. The data were labelled using descriptive codes to simplify the complexity and then sorted into manageable units. The patterns were identified based on these labels and were assimilated into broader categories. The major topics and themes helped identify the concepts and central ideas. The data gathered through critical incidents were analysed in the same manner. Documents, archival records, physical and cultural artefacts were used to validate, support and explore the qualitative data.

\section{Results}

Effectiveness of Ministry of Education inspection and school-based supervision

Ministry of Education inspection system. Even though legislatively mandated, MoE inspection was criticized by the interview subjects regarding the 'inspector quality' and the 'nature of the process'.

Inspector quality. Teachers considered inspectors as perfectionist, judgemental and incompetent. Inspectors were considered domineering, as if observing from an 'ivory tower' viewpoint. It is stated that rather than evaluation, the review turned from the teacher's qualifications to inspector's discussing their own qualifications. Teachers contended that inspectors dominated discussions and even interfered with lessons in progress.

Teachers also stated that inspectors were prejudiced due to information given them by the principal before the evaluation. Teachers contended that inspectors did not have a constructive attitude; one teacher stated:

It is inevitable that the teachers are discouraged as a result of this process . . it is unlikely that an inspector would like a lesson; they always find something negative to say.

Further, inspectors were cited as being 'incompetent' regarding subject-matter and their inspection ability. Teachers stated that inspectors showed little knowledge of current teaching practices and methods, and did not follow universally accepted inspection procedures. One teacher explained:

To improve something there needs to be an efficient feedback system. Further, the inspectors do not place any effort or importance on improving the method of instruction.

Inspection process. Regarding the nature of $\mathrm{MoE}$ inspection, the process was viewed as summative and biased, rather than formative. The numbers, however, are against the inspectors. There were not enough inspectors to perform comprehensive review of the school systems. One assistant head, who had worked as a MoE inspector, explained that each inspector had 150 teachers to evaluate. He said there are only 85 working days per school term, which approximated to half of the teachers required 
to be inspected. It is physically impossible for one inspector to travel, settle in and, day after day, repeat evaluation of teachers. One teacher emphasized:

what the inspectors see is not the natural context; they observe each teacher only once or twice during the teachers' professional tenure and the evaluation is seen as only synonymous with minimal observation.

Most teachers believed that ministry inspectors are easily deceived. One teacher said:

if wanted, a different classroom image can be presented, which is acceptable to the inspectors. A lesson parallel to the inspector's assumption can be prepared.

One department head shared the same opinion, saying:

inspectors cannot judge the teacher within this short time frame and this justifies the schools having their own school-based evaluation system.

Another teacher also expressed that inspection should not be performed solely for the sake of having the inspection, but each participant should benefit from the activity. Teachers felt that they are judged on certain traits, characteristics, styles or behaviours only important to the MoE.

Along these lines, the study indicates that teachers did not believe in the current MoE inspection. They contended that inspectors had based teacher evaluation according to their own political preferences, although it is the MoE's written policy that inspectors should not be biased by political or religious affiliations and judgements should be made solely on teacher performance. The teachers also believed the MoE inspection to be 'subjective' due to ill-defined written criteria. They also felt that greater priority is placed on the required paperwork, rather than in-class performance.

School-based supervision system. The data reveal that the SBS system was considered necessary by the respondents for various reasons. First, serving in a private school, the administration felt obliged to respond to high parental expectations. Similarly, teachers agreed that management, in order to satisfy the expectation of the parents, should recruit qualified teachers, assess their performance continuously and provide training opportunity to all teachers. Even with the common agreement on the necessity for an SBS system, most subjects expressed the following concerns.

Lack of purpose in teacher evaluation. Teachers stressed that the school does not have a clear written teacher evaluation policy. They contended that lack of clarity created discord between the principal and teachers over the perception of the evaluation. The principal admitted that the primary goal of the teacher evaluation was to improve teaching quality by 'weeding out' those teachers who offer little or no future school benefit. The teachers saw the system as being 'intrusive', appropriate only for administrative purposes, such as contract renewal, and not at all formative.

Teachers complained that there was no 'standard criterion' as to who was to be evaluated, what was to be evaluated and what kind of instruments were to be used during the evaluation. However, the principal did not view lack of standard criteria as a weakness since 'even the MoE does not have consistent written criteria'. 
Poorly performed class observation. All teachers mentioned that class performance observation did not conform to the pre-observation, observation and post-observation stages. Teachers complained that they were passive participants in the evaluation system. They contended that the principal determines when visits will be conducted without their consultation, and mentioned that there was always an element of stress and overreaction by both students and teachers during the observation. The principal's presence caused teachers to take a centre-stage approach in order to demonstrate or act out their expected behaviour. It is the common belief that the principal's intrusive monitoring and physical presence modified the setting and resulted in false impressions.

In contrast, the principal perceived his unstructured class observations as an opportunity to see the natural atmosphere of the class. The principal felt that, if informed beforehand, the teachers would place extra effort on the lesson.

From the students' perspective, they did not count these visits either as a strength or a weakness since it made little difference whether the principal came announced or unannounced; they felt that they had to behave themselves in either situation. The teacher, as they saw it, will treat them based on their performance and behaviour during the visit. Therefore senior students indicated that it in inevitable that both their teachers and they themselves change their behaviours in a positive manner during visits, whereas juniors saw their teachers as respected figures and were more uncomfortable during the principal observation. Almost all students and teachers said that the principal did not stay long enough to have a contextual understanding.

Lack of feedback and reinforcement. The overall teacher perception of feedback is that 'if the principal is satisfied with the teacher's performance, no feedback is offered'. However, teachers did not approve the 'no problem, no feedback' approach, some even saw this attitude as insulting. They stated that even effective teachers want their performance to be recognized and reinforced by the administration.

In general, the data reveal that there is no written feedback, but only some form of verbal feedback. The principal argued that as long as there is minimal verbal feedback, there is no need to show a written document to the teachers. It was his belief that when people are presented their weak points in written form they become disappointed and their positive attitude and performance decrease. Contrary to this, all teachers expect individual verbal and written feedback, rather than anonymous examples.

From the data it appears that contract renewal is the only reinforcement for the teachers. Teachers explained that during this time their frustration is extremely high. The administration renewed the contracts in June, and if a teacher's contract is not renewed, they have difficulty in securing another position. The data show that the attitude towards teacher evaluation and follow-up decisions on contract renewal causes uneasiness and 'invisible' competition among teachers. Teachers stated that attitudes towards the evaluation system could become so negative and emotional that nothing positive was achieved for the teachers or the instructional process. 
Lack of student and parent input into the evaluation process. Teachers accept student involvement in the evaluation process. However, the students' objectivity is of concern to the teachers. They contended the students' maturity level did not permit objective evaluation, and further, that the 'student instructor evaluation questionnaire', administered by a school counsellor on an annual basis, had inadequate format and content. Even students agreed that this questionnaire was poorly designed; they believed they could evaluate teachers in terms of subject-matter knowledge and class effectiveness. However, their concerns were different from those of the teachers. First, some students worried about potential negative treatment from the teachers if they honestly responded to the questions. Secondly, they believed neither the counsellors nor the teachers took the forms particularly seriously, and indicated that even if they tried to evaluate their teachers objectively, nothing would change, and they were not informed regarding results.

Parental involvement is seen by the administration and staff only to occur when parents have a problem with a particular teacher and, therefore, lend little basis to these periodic assessments.

Impact of these systems on teaching and learning context, teacher development and overall school improvement

Most teachers contend that the MoE inspection has little or no impact on the teaching and learning context. They resented this inspection and viewed it as nonacademic, a hindrance to their class time and a waste of their energies. Teachers regarded the school administration's reliance on $\mathrm{MoE}$ inspection as a basis for supplemental information regarding teacher performance as highly questionable. Inspection reports, however, do in some instances have positive results. The principal stated that these reports, though administrative, acknowledge individual teacher performance. This acknowledgement is shown by issuance of letters of outstanding performance; the school recognizes these letters as an achievement on the teachers' part and gives credit for having received such documents during contract renewal.

As pointed out by the principal, departments prepare extensively for inspection. A good report enhances accountability to major stakeholders. This inspection only served to audit the administrative side of the school, and therefore as contended by the teachers, did not add significantly to their improvement. The stated role of the $\mathrm{MoE}$ is to improve and maintain minimal educational levels; however, teachers stated that due to either staffing and/or lack of direction within the $\mathrm{MoE}$, it failed to foster a programme leading to competent teacher improvement.

In terms of the school-based supervisory practices, teachers believed the school procedures did not exemplify good methodology. The diversity of opinions on this issue result from various views on the purpose of supervision and the role assigned to the supervisor, in this instance, solely the principal. Teachers contended that the supervisory practices are only an administrative assessment identifying weak teachers and making only personnel decisions.

The current teacher supervision is viewed by teachers as having a negative impact due to its 'summative' nature. They pointed out that the system causes fear of 
dismissal, frustration and unneeded competition among teachers. Some teachers expressed the opinion that good teachers maintain their own quality attributes without control and that this self-control is part of being a professional.

The teachers and some of the administrators concluded that supervisory practices create tension and unhappiness among most teachers, and felt that these practices are useless. They also felt that the teachers are considered a homogeneous group, rather than individuals who function at different stages of cognitive, personal and moral development. However, there is a group of teachers who believed these impacts, ultimately and surprisingly, could lead to a positive impact on teacher development and school improvement; teacher development relates closely to the level of a given teacher's personal desire to enhance their professional and personal maturity. The teachers stated that, based on the fear of dismissal, the 'professional' development is the teacher's desire for the enrichment of knowledge, improved teaching techniques and awareness of improvement opportunities.

All respondents agreed that: 'improvement in teaching and learning processes with quality teachers will inevitably lead to overall school improvement.' Because of its private status, the school must maintain a strong staff in terms of their subject knowledge, with a positive teaching attitude and commitment to school improvement. It is the subjects' belief that the evaluation system was working very efficiently, in this sense, and that the school had a group of committed teachers. It is the common feeling that if the teachers are strong in a particular school, then that school will attract more students, and that, in turn, the school's administration earns more profit and can provide more benefits to the teachers, which results in added improvements in the school. This is a constructive cycle.

\section{Discussion}

When comparing centralized and school-based supervision systems, it is apparent that each system has both strengths and weaknesses. The literature suggests that a combination of 'internal self-evaluation' and 'external inspection' tends to be more effective than a mono-inspection method (Hargreaves, 1995), so long as they do not duplicate each other's function.

Until only recently, the Turkish education system has clung to a rigidly controlled arrangement. The MoE still maintains legislative mandated control; however, the private school sector has implemented its own 'supplemented inspection' to meet market demands of results-oriented stakeholders. As previously mentioned, the private school sector has shown, statistically, higher university entrance rates when compared to public schools.

The school studied expounded one goal as to focus on instructional improvement; however, supervision's prime aim is to rid the organization of incompetent teachers due to competition from other private schools. Likewise, the MoE pressures 'the inspected to conform' (Hargreaves, 1995). Neither the MoE nor the school give feedback to teachers (Collins, 1999, 2000), and this was reported by the OECD as early as 1990 (OECD, 1990). 
Unfortunately, the coalescence of the two systems, with its double-edged sword effect, fails to provide any developmental feedback. Neither goes any further than checking the necessary managerial requirements and using the system to maintain institutional control. Both supervision systems are founded on negative reinforcement. The teachers are compelled to compete for a place in the school, even without incentives or receiving a higher salary; incentives and merit pay have been passed over in favour of threats and dismissal. All of these motivators lead to stress and fear among the staff. These fears manifest in teachers undertaking self-improvement in an effort to assure continued employment. Even the mere fact of inspection raises anxiety levels which may lead to 'physical and emotional problems' (Brimblecombe \& Ormston, 1995; Gray \& Gardner, 1999).

\section{Recommendations}

With the understanding that only a major shift in Turkish education policy would bring about decentralization of the entire system, this study recommends that a modified system be implemented as a pilot study in a portion of the private schools sector (Figure 1). It would be one that met the mandated central inspection system

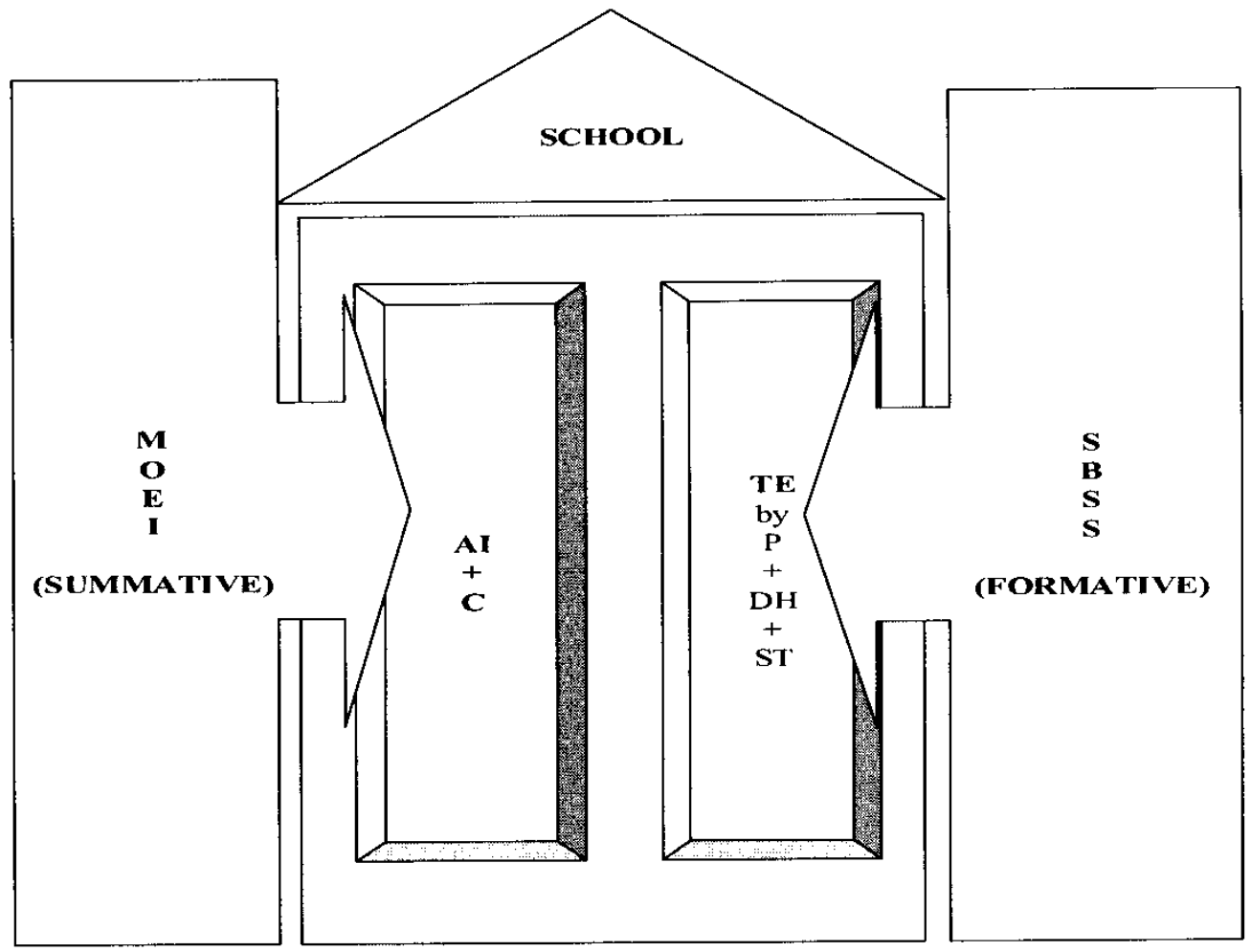

Figure 1. Combination of $\mathrm{MoE}$ inspection and SBSS ( $\mathrm{AI}=$ administrative inspection; $\mathrm{C}=$ certification; $\mathrm{TE}=$ teacher evaluation; $\mathrm{P}=$ principal; $\mathrm{DH}=$ department heads; $\mathrm{ST}=$ senior teacher) 
and grasped the benefits of the SBS system. It is envisioned that the MoE would continue to conduct its inspection of schools from its administration viewpoint, but would institute a programme that trained and certified school-based inspectors (principals, department heads or senior teachers). This training and certification would be conducted by the senior inspection staff, most of whom had been trained in educational techniques. In turn, the schools would perform their own teacher evaluations. Based on these evaluations, the schools would then undertake a programme to address the individual needs of teachers and school development.

First, they would be better equipped to tailor inspection schedules, have intimate knowledge of their teachers and provide comprehensive reports listing teacher strengths and weaknesses based on effective teacher literature. Secondly, the reports would be used by the school to implement a programme of teaching methods. Thirdly, the reports would be shared with the teachers, to address their concerns over 'no problem/no feedback'. Moreover, by including department heads and senior teachers who would be subject knowledgeable as inspectors, a comprehensive inspection would be performed and the principal supplemented in his duty of teacher performance evaluation.

Further, the developmental approach would, in essence, provide the school with the opportunity to shape its own direction and offer the teachers a feeling of accomplishment and advancement. Supervision would have direct involvement in shaping skills and teaching methods that were deemed most effective to their specific system. The two-level system could be tailored to provide time-based 'snapshots' of the existing system, while allowing local analysis of specific performance, progress and achievement for future reference.

If the pilot study was found effective, the MoE could use the model as a carry-over to the remaining private schools, thereby relieving some of the imbalanced mix of inspectors to teachers. This, in essence, would bring the whole school system up to a higher level. By doing so nationwide, data and national performance, based on university entrance, could be gauged and local needs addressed. As in other countries, the quality of those who inspect in Turkey would be raised, their techniques and methodology improved (Gray \& Gardner, 1999).

\section{Conclusion}

The need for an operating supervision system in all schools is a requisite to quality education. Even if no more than a monitor, its presence assures that there is an authority to whom educational activities are accountable. The key, however, is the balance by which the supervision system attains the goals set for the individual school. A balanced system is certainly desirable if equilibrium is to be achieved when uniting two divergent methodologies such as the centralized and decentralized inspections. In order to complement each other, one of the two systems cannot duplicate the other. The MoE is a mandated system and hard to change, whereas school-based systems are a creation of change. Schools under both the centralized and decentralized tracts must have the vision and political determination to set high goals for themselves and be willing to make those changes which benefit students, as well as teachers. 
Changing the educational policies of a country is a difficult process. Turkey is no exception to this case, and is not at the stage where drastic shifts in both social and political mentalities regarding education can be readily assimilated into the existing bureaucratic system. If the MoE is based on summative policy, then the SBS should assume a quasi-formative policy. By doing so, a balance may be achieved and, ultimately, the working system have the best of both worlds.

\section{References}

Bacharach, S. B., Conley, S. C. \& Shedd, J. B. (1990) Evaluating teachers for career awards and merit pay, in: J. Millman \& L. Darling-Hammond (Eds) The new handbook of teacher evaluation (Beverly Hills, CA, Sage).

Barr, A. S., Burton, W. H. \& Brueckner, L. J. (1961) Wisconsin studies of the measurement and prediction of teacher effectiveness: a summary of investigations, fournal of Experimental Education, 30(1), 1-153.

Bridges, M. E. (1990) Evaluation for tenure and dismissal, in: J. Millman \& L. Darling-Hammond (Eds) The new handbook of teacher evaluation (Beverly Hills, CA, Sage).

Brimblecombe, N. \& Ormston, M. (1995) Teachers' perception of school inspection: a stressful experience, Cambridge fournal of Education, 25(1), 53-62.

Carroll, J. B. (1963) A model of school learning, Teachers College Record, 64, 723-733.

Cogan, M. (1973) Clinical supervision (Boston, MA, Houghton-Mifflin).

Collins, B. A. (1999) A case study of instructional supervision at a private secondary school, unpublished doctoral dissertation, Middle East Technical University, Ankara, Turkey.

Collins, B. A. (2000) Impact of centralised instructional supervision on teachers: a case study of a private secondary school in Turkey, Mediterranean fournal of Educational Studies, 5(2), $1-18$.

Dewey, J. (1929) The sources of a science of education (New York, Horace Liveright).

Duke, D. L. \& Stiggins, R. J. (1990) Beyond minimum competence: evaluation for professional development, in: J. Millman \& L. Darling-Hammond (Eds) The new handbook of teacher evaluation (Beverly Hills, CA, Sage).

Eisner, E. W. (1982) An artistic approach to supervision, in: J. T. Sergiovanni (Ed.) Supervision of teaching: 1982 yearbook (Alexandra, VA, Association for Supervision and Curriculum Development).

Gagné, R. M. (1967) The conditions of learning (New York, Holt, Rinehart and Winston).

Garman, B. N. (1982) The clinical approach to supervision, in: J. T. Sergiovanni (Ed.) Supervision of teaching: 1982 yearbook (Alexandra, VA, Association for Supervision and Curriculum Development).

Gray, C. \& Gardner, J. (1999) The impact of school inspection, Oxford Review of Education, 25(4), $455-469$.

Hargreaves, D. H. (1995) Inspection and school improvement, Cambridge fournal of Education, 25(1), 117-128.

Iwanicki, E. F. (1990) Teacher evaluation for school improvement, in: J. Millman \& L. DarlingHammond (Eds) The new handbook of teacher evaluation (Beverly Hills, CA, Sage).

Knapp, M. S. (1982) Toward the study of teacher evaluation as an organizational process (Menlo Park, CA, Educational and Human Resources Research Center).

Ministry of Education (1999) Statistics in national education (Ankara, Turkish Ministry of Education Printing Office).

OECD (1990) Turkish national educational policy analysis (OECD Report) (Ankara, Turkish Ministry of Education Printing Office).

Oliva, P. (1989) Supervision for today's school (New York, Longman).

Poster, D. C. (1991) Teacher appraisal: a guide to training (New York, Routledge). 
Sergiovanni, J. T. (1982) Toward a theory of supervisory practice: integrating scientific, clinical, and artistic views, in: J.T. Sergiovanni (Ed.) Supervision of teaching: 1982 yearbook (Alexandra, VA, Association for Supervision and Curriculum Development).

Wilson, T. A. (1995) Notes on the American fascination with the English tradition of school inspection, Cambridge fournal of Education, 25(1), 89-97. 